\title{
INTELIGÊNCIA EMOCIONAL: CONTRIBUTOS ADICIONAIS PARA A VALIDAÇÃO DE UM INSTRUMENTO DE MEDIDA ${ }^{1}{ }^{\mathrm{e}_{2}}$
}

\author{
Arménio Rego ${ }^{3}$ \\ Cláudia Fernandes ${ }^{4}$
}

Resumo: O artigo faculta evidência empírica adicional para a validação de um instrumento de medida da Inteligência Emocional sugerido por Rego e Fernandes (no prelo). Os indivíduos da primeira amostra foram convidados a responder ao questionário sugerido por esses investigadores e a declarar os seus níveis de saúde-doença física. Os indivíduos da segunda amostra, após reportarem os seus níveis de IE, foram convidados a declarar o grau de satisfação com a vida. Os resultados sugerem uma estrutura hexafactorial da IE: (1) compreensão das emoções próprias; (2) autocontrolo perante as críticas; (3) auto-encorajamento (uso das emoções); (4) autocontrolo emocional; (5) empatia; (6) compreensão das emoções dos outros. Estas seis dimensões explicam $14 \%$ da variância da medida de saúde física e $26 \%$ da variância da satisfação com a vida. Embora similar à extraída por Rego e Fernandes, a dimensionalização aqui obtida denota algumas vantagens relativamente a ela. Designadamente, os conteúdos semânticos dos itens relativos a cada factor são agora mais claros e congruentes com a denominação dos factores.

Palavras-chave: inteligência emocional, saúde-doença física, satisfação com a vida.

Emotional intelligence: Further contributions for validating a measurement instrument (Abstract): The paper provides further empirical evidence for validating the

\footnotetext{
${ }^{1}$ Este trabalho foi desenvolvido à luz do Projecto de Investigação POCTI/CED/ 40265/2001 - "Comportamentos de Cidadania Docente de Professores Universitários", financiado pela Fundação para a Ciência e a Tecnologia e comparticipado pelo fundo comunitário FEDER.

${ }^{2}$ Estamos muito gratos aos revisores anónimos pelos seus preciosos comentários e sugestões.

${ }^{3}$ Universidade de Aveiro, Departamento de Economia, Engenharia e Gestão Industrial. E-mail: Arego@egi.ua.pt

${ }^{4}$ Universidade de Aveiro, Departamento de Economia, Engenharia e Gestão Industrial. E-mail: cfernandes@egi.ua.pt
} 
instrument for measuring Emotional Intelligence suggested by Rego and Fernandes. The individuals of the first sample were invited to answer to the questionnaire suggested by those researchers and to report their physical health. The individuals of the second sample, after describing their IE, were invited to report their satisfaction with life. The findings suggest a six-factor model: (1) understanding of emotions in self; (2) self-control before criticisms; (3) self-encouragement; (4) emotional self-control; (5) empathy; (6) understanding of emotions in others. These dimensions explain $14 \%$ of the variance of physical health and $26 \%$ of the variance of the satisfaction with life. Although this dimensional structure is similar to the one extracted by Rego and Fernandes, it has some advantages. For example, the semantic contents of the items comprised in each factor are now closer to the meaning of each dimension.

\section{Introdução}

Este artigo visa expor evidência empírica adicional acerca do instrumento de medida da inteligência emocional (IE) desenvolvido e validado por Rego e Fernandes (no prelo). A análise das componentes principais executada pelos investigadores sugeriu um modelo hexadimensional: (1) sensibilidade emocional; (2) empatia; (3) compreensão das emoções próprias; (4) auto-encorajamento; (5) compreensão das emoções dos outros; (6) autocontrolo emocional. A clareza desta estrutura factorial, as elevadas saturações factoriais e os satisfatórios níveis de consistência interna reflectem boas propriedades psicométricas. Todavia, a análise semântica dos descritores imputados a cada factor faz assomar alguns problemas de interpretação e sugere a necessidade de se proceder a trabalho empírico adicional que permita aclarar o significado de cada dimensão.

É neste quadro que se situa este artigo. Para que se compreenda o quadro teórico em que se insere a IE, são tecidas considerações prévias sobre diversas matérias: (a) proceder-se-á a uma análise das raízes históricas do conceito; (b) discutir-se-á o nexo emoção-razão; (c) reflectir-se-á sobre a pertinência de a IE ser considerada um constructo autónomo; (d) abordar-se-ão os impactos e os benefícios da IE; (e) expor-se-á evidência acerca dos métodos, dos instrumentos de medida e das dimensões de IE identificáveis na literatura. Após a análise crítica do instrumento de medida antes aludido, reportar-se-á a metodologia usada na presente pesquisa, apresentar-se-ão e discutir-se-ão os resultados e expor-se-ão pistas de reflexão sobre investigações vindouras que possam aprimorar as propriedades psicométricas do constructo. 


\section{Raízes históricas da IE}

A IE, a par da inteligência social (Thorndike, 1920) e da inteligência prática (Sternberg, 1985, 1997), insere-se no rol das inteligências designadas não académicas (Sternberg, 1985, 1997), não cognitivas (Bar-On, 1997) ou não intelectivas (Weschler, 1940, 1943). Estas denominações tentam descrever formas menos tradicionais de abordar o conceito de inteligência, na maior parte dos casos contrapondo-se ao QI e às capacidades cognitivas. O termo "Inteligência Emocional" foi formalmente definido, pela primeira vez, no dealbar da década de 90 por Salovey e Mayer (1990). Todavia, as suas raízes situam-se no conceito de "inteligência social" identificado por Thorndike (1920): "capacidade de compreender e gerir, homens e mulheres, rapazes e raparigas - actuando sabiamente nas relações humanas". Ao preconizar a teoria das inteligências múltiplas, Gardner (1983) viria a considerar esta forma aventada por Thorndike como uma das sete inteligências, tendo-lhe identificado duas vertentes: (1) a intrapessoal, que é a capacidade de auto-avaliação e de conhecimento dos próprios sentimentos; (2) e a interpessoal, que envolve a capacidade de compreender os "estados de espírito" e os desejos dos outros e de agir com base nestes conhecimentos.

Na definição de Salovey e Mayer (Mayer \& Salovey, 1997; Salovey \& Mayer, 1990), a IE é uma vertente da inteligência social, envolvendo a competência para percepcionar e expressar emoções, compreendê-las, usá-las e geri-las em si próprio e nas outras pessoas. Mais formalmente, engloba quatro competências: (1) capacidade de percepção, avaliação e expressão de emoções; (2) capacidade para aceder e gerar sentimentos que facilitem as actividades cognitivas; (3) capacidade para compreender e analisar informação emocional e para usar o conhecimento emocional; (4) e capacidade de regular emoções para promover o desenvolvimento e o bem-estar emocional e intelectual.

\section{Emoção e razão}

Um dos aspectos mais contributivos do desenvolvimento do constructo de IE foi o conceito de emoção. Esta foi tomada como um elemento necessário para o desenvolvimento das operações mentais, a par com a motivação e a cognição (Bechara et al., 2000; Harris, 2000; Izard \& Ackerman, 2000; Johnson-Laird \& Oatley, 2000; Kemper, 2000; Mayer \& Salovey, 1993; Saarni, 2000; Sterns, 2000). Esta tese colidiu com a ideia até então vigente que pugnava pela contradição ou antagonismo entre os conceitos de inteligência e de emoção (Grandey, 2000; Mayer \& Salovey, 
1997). Era, então, premissa comum a ideia de que, por exemplo, a tomada de boas decisões implicava que se arredasse a emoção das mesmas. Ao arrepio dessa tese, Mayer, Salovey e seus colaboradores argumentaram que a IE é, em medida considerável, o resultado profícuo da interacção entre as emoções e as cognições (Mayer \& Salovey, 1995, 1997; Mayer et al., 2000a): (a) a emoção torna o pensamento mais inteligente; (b) a inteligência cognitiva auxilia o indivíduo a pensar as suas emoções e as dos outros; (c) a ausência desta relação binomial torna o indivíduo emocional e socialmente incapaz.

Estas proposições sorveram influência, entre outras fontes, nos trabalhos de Mowrer (1960) e de Payne (1986). Por exemplo, para Mowrer, as emoções não se opõem à inteligência, antes parecendo ser uma inteligência de mais elevada ordem. Em resumo, os autores aduzem que os indivíduos variam nas suas capacidades de processamento de informação de natureza afectiva e na forma como a relacionam com formas de cognição psicologicamente complexas. Estas capacidades manifestam-se em formas de comportamentos adaptativos. Em prol da pertinência do conceito são apresentados estudos clínicos de desordens do foro psicológico/psiquiátrico, como, por exemplo, a alexitimia (Taylor, 2001; Taylor \& Bagby, 2000; Taylor et al., 2000). Diversos estudos nas áreas da neurologia e da psicofisiologia têm contribuído para compreender o cérebro humano, para interpretar a sua relação com o resto do corpo e para compreender a interacção que se estabelece entre as emoções e o processamento da informação. Deles tem provindo primordial apoio ao desenvolvimento e validação do constructo de IE, fornecendo evidência empírica acerca da pertinência e da aplicação prática do mesmo.

\section{A IE como constructo autónomo}

Um passo imprescindível para a consideração de uma "nova" inteligência é aferir a sua autonomização relativamente a outros tipos de inteligência já identificados e/ou a medidas de personalidade (Mayer et al., 2001). Este foi, aliás, um dos argumentos aventados para criticar o conceito de inteligência social, aduzindo-se que ela se não distinguia suficientemente de outras variáveis da personalidade e da inteligência (Cronbach, 1960; Mayer \& Salovey, 1993, 1997; Thorndike \& Stein, 1937). Algumas críticas projectadas sobre a IE apontam na mesma senda, considerando-a uma espécie de "repescagem" da inteligência social e, por conseguinte, padecendo dos mesmos problemas psicométricos. Um dos estudos porventura indutores de maior reflexão sobre a matéria foi realizado por Davies e colaboradores (1998). No cabo do trabalho empírico, os autores asseve- 
raram que os três estudos realizados convergiam para uma conclusão: "pouco pode ser identificável de único e psicometricamente sólido na inteligência emocional" (p. 1013). Em sustentação da tese, aduziram que: (a) os questionários de medida se relacionavam fortemente com determinados traços de personalidade (sugerindo, pois, não haver validade discriminante suficiente); (b) as medidas objectivas denotavam fraca fidedignidade. Todavia, alertaram para a validade de constructo de uma dimensão de IE (percepção de emoções) e sugeriram a necessidade de se desenvolverem instrumentos de maior valia psicométrica - o modo apropriado de testar se, de facto, estamos perante uma forma específica de comportamento ou, antes, de traços de personalidade mais ou menos impregnados na literatura. Ante este cepticismo, os principais "progenitores" científicos actuais da IE (Mayer \& Salovey) têm aduzido motivos vários para edificar a tese da validade da autonomização da IE - relativamente à inteligência geral, a outras formas de inteligência e a traços de personalidade. Eis alguma argumentação pertinente:

A IE focaliza-se mais na resolução emocional de problemas do que em aspectos sociais, verbais e visuais tão conexos com o conceito de inteligência social (Mayer \& Geher, 1996; Mayer et al., 2000a). Esta distinção transcorreu, aliás, para a definição de IE enquanto subcategoria da inteligência social. Na verdade, Salovey e Mayer (1990) definiram-na como "a subcategoria da inteligência social que envolve a capacidade de monitorar os sentimentos e as emoções, tanto em si próprio como nos outros, a capacidade de estabelecer distinções entre eles e a capacidade para utilizar esta informação na condução das suas próprias acções e pensamentos" (p. 189).

Há razões para presumir que a IE, relativamente à inteligência geral, denota maior validade discriminante do que a inteligência social. Na verdade, a IE envolve o processamento e a manipulação de emoções - campo mais específico do que a inteligência social, cuja definição ampla a torna por vezes dificilmente destrinçável das inteligências verbal e visual-espacial (Mayer \& Salovey, 1993). Há razões para supor que a IE se correlaciona de modo suficientemente elevado com a inteligência geral para ser considerada uma forma de inteligência - mas de modo suficientemente fraco para não ser tomada como parte integrante da inteligência geral e ser, antes, tomada como uma forma de inteligência autónoma.

Aspectos como a extroversão, a autoconfiança, a baixa ansiedade e a perceptividade social, embora correlacionados com a inteligência, não são inteligência (Mayer \& Salovey, 1993; Scarr, 1989). Por exemplo, enquanto a extroversão envolve disposições tendentes ao comportamento, a inteligência envolve competências "organísmicas" para o comportamento (Mayer \& Salovey, 1993, p. 435). A extroversão é um traço que depende de competências sociais - ou que pode confluir para as mesmas. Mas é 
mais uma preferência comportamental do que uma competência. Distintamente, saber o que uma pessoa sente é uma capacidade mental - algo que representa inteligência, seja ela provinda da inteligência geral ou uma forma de inteligência independente (Mayer \& Salovey, 1993, 1997).

Em jeito de síntese, pode afirmar-se que está formada consciência generalizada (Kaufman \& Kaufman, 2001; Mayer et al., 2001; Roberts et al., 2001; Zeidner et al., 2001) sobre duas matérias. Primeira: os diversos trabalhos desenvolvidos acalentam a expectativa de que se esteja no caminho certo. Segunda: o desenvolvimento de um constructo de IE com características autonómicas requer ainda inúmeros anos de escrutínio e pesquisa (Mayer et al., 1999, 2001), exemplo, aliás, do que ocorreu com uma das escalas de inteligência mais utilizadas na sua aferição - a Escala de Inteligência de Wechsler, um produto de mais de 60 anos de investigação e de desenvolvimento.

\section{Impactos e benefícios da IE}

A IE tem experimentado um especial desenvolvimento nas áreas educacional e da psicofisiologia (Dulewicz \& Higgs, 2000). São também identificáveis trabalhos aplicados ao contexto militar e outros destinados ao desenvolvimento pessoal e grupal dos indivíduos (Livingstone \& Nadjiwon-Foster, 2002). Uma das matérias empíricas que tem vindo a ser investigada é a relação entre IE e a satisfação com a vida e com o trabalho. Por exemplo, Wong e Law (2002) notaram que a IE dos líderes se correlaciona fortemente com a satisfação e o empenhamento dos colaboradores. Ciarrochi et al. (2000) verificaram que a IE se relaciona com a satisfação com a vida, mesmo depois de se controlarem variáveis como o QI e outras variáveis de personalidade. Também Palmer et al. (2002) notaram que um dos factores de IE ("clarity") explica cerca de 5,5\% da satisfação com a vida, para além da variância explicada por outros factores de personalidade estudados (afectividade positiva e afectividade negativa).

Também a área organizacional tem sido alvo de prolixa investigação. Um dos temas objecto de maior atenção tem sido a liderança (Barling et al., 2000; Caruso et al., 2001; George, 2000; Goleman, 1998, 1999, 2000; Goleman et al., 2001, 2002; Megerian \& Sosik, 1996; Wong \& Law, 2002). Por exemplo, algumas investigações sugerem que quase noventa por cento das competências necessárias para o sucesso da liderança são de natureza emocional e social (Goleman, 1998). Numa visão sinóptica, a diversa evidência teórica e empírica produzida é reveladora de que: (a) os líderes emocionalmente mais inteligentes tendem a ser mais eficazes na consecução dos objectivos do grupo/organização, assim como na satisfação e 
realização pessoal dos seguidores; (b) diferentes situações de liderança requerem diferentes combinações de competências emocionais; (c) os efeitos positivos que têm vindo a ser apontados à liderança transformacional podem ser explicados, em medida considerável, pelas competências emocionais que os líderes denotam. São estas que suportam a articulação da visão, a consideração dos colaboradores, a criatividade no processo decisório, a gestão construtiva dos conflitos e a interacção frutuosa dos membros da equipa.

No quadro mais geral das relações entre IE e desempenho e sucesso profissional dos indivíduos, algumas asserções permitem resumir a matéria (e.g., Cherniss, 2000; Dulewicz \& Higgs, 2000; Farnham, 1996; Goleman, 1995, 1999; Goleman et al., 2001, 2002; Salovey \& Mayer, 1990; Steiner, 1997; Wong \& Law, 2002): (1) as aprendizagens de sucesso e os mais elevados desempenhos surgem da reunião sinérgica das capacidades racionais e emocionais; (2) a combinação do QI e da IE explica uma maior variação no desempenho do que apenas o QI; (3) para que a IE exerça efeitos positivos sobre o desempenho dos indivíduos, é necessário que estes disponham de um patamar mínimo de QI; (4) por conseguinte, o QI parece necessário, mas não suficiente, carecendo os seus efeitos positivos da presença da IE; (5) de modo similar, a IE carece da presença do QI para que possa suscitar mais elevados desempenhos.

Esta evidência, agregada à convicção provinda do senso "comum", ajuda a compreender as razões pelas quais têm surgido diversos projectos e eventos formativos destinados a fomentar a IE. A premissa subjacente é a de que, embora a IE tenha uma componente de raiz genética, a investigação sugere que o treino/formação também pode produzir efeitos. O que corresponde a cada uma destas duas parcelas é de difícil escrutínio - "mas a pesquisa e a prática demonstram claramente que a inteligência emocional pode ser aprendida" (Goleman, 1998, p. 97).

Refira-se, ainda, que estudos acerca do desenvolvimento emocional dos grupos têm também sido desenvolvidos. Segundo Barsade (2002), os membros de um grupo, para além de partilharem alguns esquemas de processamento cognitivo da informação, assim como pensamentos, ideias e memórias, também partilham emoções e estados emocionais. Das suas pésquisas aflora a ideia, empiricamente apoiada, de que os indivíduos são "indutores activos de estados emocionais" e que influenciam activamente os julgamentos, as racionalizações e os comportamentos dos outros - podendo embora não ter consciência desse impacto.

Druskat e Wolff (2001) também se debruçaram sobre a IE dos grupos, embora num plano não exactamente coincidente com o percorrido por Barsade. Os autores aduziram, entre outros argumentos, os seguintes: (a) as equipas emocionalmente inteligentes denotam níveis de desempenho supe- 
riores; (b) são conscientes das emoções individuais dos seus membros e aceitam regulá-las; (c) os membros dessas equipas confrontam-se entre si quando infringem as normas de funcionamento do grupo (e.g., ausência de julgamentos e não exclusão de ideias nas sessões de brainstorming); (d) as equipas procuram constantemente feedback que lhes permitam ter "autoconsciência"; (e) as equipas têm normas para se assegurarem de que estão conscientes das necessidades e preocupações das pessoas exteriores ao grupo e que usam essa consciência para desenvolverem relações com esses indivíduos e grupos. Druskat e Wolff afirmaram ainda a tese de que pessoas emocionalmente inteligentes não suscitam necessariamente organizações e grupos emocionalmente mais capazes. Huy (1999) afinou eloquentemente pelo mesmo diapasão: "Distintamente da inteligência emocional [dos indivíduos], a capacidade emocional [das organizações] não é sequer parcialmente inata, pode ser desenvolvida no decurso do tempo, e não requer necessariamente um grande número de indivíduos emocionalmente inteligentes ocupando posições influentes" (p. 326). Mais adiante, aduziu mesmo que uma organização prenhe de indivíduos emocionalmente inteligentes pode dar origem a uma organização deficitária em capacidade emocional.

\section{Métodos, instrumentos de medida e dimensões da IE}

A análise da literatura permite notar a existência de distintos métodos e instrumentos de medida da IE (e.g., Bar-On, 1996; Ciarrochi et al., 2000; Davies et al., 1998; Dawda \& Hart, 2000; Goleman, 1999; Goleman et al., 2002; Mayer et al., 2000a, 2000b; Mayer \& Salovey, 1997; Schutte et al., 1998; Tapia, 2001; Wong \& Law, 2002). Todavia, não há consenso entre os investigadores acerca de qual o melhor método (Dulewicz \& Higgs, 2000). Salovey e seus colaboradores (Salovey et al., 2001) foram, aliás, paradigmáticos: "Existe bastante convergência entre os investigadores acerca do que é a inteligência emocional - um conjunto de competências que engloba a avaliação e a expressão de emoções, o uso das emoções para facilitar as actividades cognitivas, o conhecimento acerca das emoções e a regulação das emoções. Há, todavia, menos consenso acerca de qual o melhor método para medi-la" (p. 289).

Podem identificar-se, fundamentalmente, três tipos de métodos: (1) testes de competências; (2) questionários de autodescrição; (3) método dos informadores (Mayer et al., 2000b). Nos testes de competências, o indivíduo é induzido a desempenhar diversas tarefas, entre as quais a resolução de problemas que implicam/pressupõem haver uma resposta "correcta" e, portanto, reveladora de mais elevada IE. Um exemplo ilustrativo é o 
MEIES - Multifactor Emotional Intelligence Scale (Mayer et al., 2000b). Entre as maiores dificuldades inerentes a estes testes estão a dificuldade de seleccionar as tarefas mais pertinentes e a de determinar a resposta mais condizente com o conceito de IE.

Nos questionários de autodescrição, os indivíduos são convidados a autodescreverem-se mediante as respostas a diversas afirmações. Exemplos ilustrativos são o EQ-i desenvolvido por Bar-On (1996), o instrumento sugerido por Wong e Law (2002) a partir da tetradimensionalização próposta por Mayer e Salovey (1997) e o Trait Meta-Mood Scale (Salovey et al., 1995). Presume-se que as pessoas denotam capacidades de auto-análise e de autoconhecimento, mas há razões para supor a possibilidade de as pessoas perfilharem um autoconceito desajustado (Taylor \& Brown, 1988). Por outro lado, em determinados casos, os indivíduos são confrontados com descritores potencialmente indutores de respostas enviesadas pela desejabilidade social. A título ilustrativo, é isso que pode ocorrer perante os itens "Não sou uma pessoa criativa" ou "Sou indiferente à felicidade dos outros". Por conseguinte, algumas escalas autodescritivas podem reflectir o autoconceito do indivíduo e/ou as suas percepções de desejabilidade - mas não a sua "real" IE. Importa, todavia, notar que o método comporta diversas vantagens, designadamente: (1) é de mais fácil aplicação; (2) permite recolher respostas de um maior número de respondentes; (3) e é mais barato. E cabe referir que diversas medidas desta natureza têm denotado consistências internas satisfatórias e validade preditiva assinalável (veja-se um breve resumo em Salovey et al., 2001).

No método dos informadores, é solicitado a observadores (e.g., colegas de trabalho, superiores hierárquicos, colegas de turma) que posicionem um determinado indivíduo relativamente a algumas afirmações. Esta via tem a vantagem de evitar os enviesamentos potencialmente advenientes das autodescrições (e.g., um indivíduo com fraca autoconsciência das suas emoções não terá autoconsciência para se descrever adequadamente nessa competência emocional). Mas comporta diversos riscos. Por exemplo, só é válida para comportamentos observáveis, pois as capacidades mentais, sendo intrínsecas ao próprio indivíduo, não podem ser acedidas desta forma. Alguns autores defendem que o método mede, fundamentalmente, a reputação de uma pessoa, e não o que ela é efectivamente (Mayer et al., 2000b). Uma das fórmulas parcialmente inibitórias destes riscos consiste em recorrer à descrição multifontes, via, aliás, usada no Emotional Competence Inventory, desenvolvido por Boyatzis e Goleman no seio da Hay/McBer (1999).

A existência de uma variedade de métodos de medida faz-se acompanhar de uma grande prolixidade de tipologias dimensionais (ver um breve resumo em Salovey et al., 2001), nem sempre coincidentes. Uma das 
mais comuns e progressivamente mais reconhecias e usadas é, porventura, a estrutura tetradimensional sugerida por Mayer, Salovey e seus colaboradores (Mayer \& Salovey, 1997; Caruso et al., 2001): (1) percepção e expressão das emoções; (2) facilitação emocional do pensamento (uso da inteligência emocional); (3) compreensão emocional; (4) e gestão das emoções. Esta estrutura reflecte o modelo de competências mentais IE (Caruso et al., 2001; Mayer et al., 2000a), o qual compete com modelos mistos - de que são ilustrativos os de Bar-On (1997) e de Goleman (1995, 1998). Designam-se mistos porque, para além das competências mentais, englobam outros aspectos da personalidade e do carácter (e.g., conscienciosidade). O modelo de Goleman é especialmente amplo, englobando 25 competências (Goleman, 1998), que se abrigam sob cinco dimensões: (1) conhecimento das emoções próprias; (2) gestão das emoções; (3) automotivação; (4) reconhecimento das emoções nos outros; (5) e gestão dos relacionamentos.

Os modelos mistos (especialmente o de Goleman) são alvo de maior popularidade, ao passo que o modelo de competências colhe maior receptividade nos meios académicos e científicos. Todavia, mais do que optar por qualquer deles, importa considerar as respectivas forças e limitações, tomando-os como complementares (Caruso et al., 2001; Mayer et al., 2000a). O presente artigo centra-se no quadro dos modelos mistos. É seu objectivo apresentar evidência empírica que visa testar o instrumento de medida previamente desenvolvido e validado por Rego e Fernandes para a população portuguesa. O quadro teórico é o dos modelos mistos, por duas razões fundamentais: (1) os itens em que assenta a validação do constructo foram recolhidos em literatura diversa - tanto a atinente ao modelo de competências mentais quanto a que concerne a diversos modelos mistos; (2) as dimensões emergentes do estudo factorial/dimensional contemplam, para além das competências mentais, outros traços e competências (e.g., empatia).

\section{Um modelo hexadimensional validado para a população portu- guesa}

Rego e Fernandes convidaram 339 indivíduos a responder a um questionário contendo 96 itens, tendo-lhes sido solicitado que respondessem à luz de uma escala tipo Likert de sete pontos (1: "não se aplica rigorosamente nada a mim"; [...]; 7: "aplica-se completamente a mim"). Os 96 descritores foram redigidos a partir de três fontes: (1) alguns foram recolhidos na literatura; (b) outros foram redigidos com base na interpretação semântica que os autores fizeram de diversa literatura também respeitante ao tema; (c) e 23 foram redigidos com base na experiência e na sensi- 
bilidade dos autores para a matéria. Esta última fonte foi sobretudo enquadrada pelo tetramodelo de Mayer e Salovey (1997). Após responderem a este questionário, os inquiridos foram convidados a assinalar o grau em que se lhes aplicavam cinco afirmações respeitantes à sua satisfação com a vida em geral (Diener et al. 1985), tendo sido usada a mesma escala tipo Likert de sete pontos antes aludida.

Os dados de IE foram submetidos a uma análise factorial das componentes principais (Bobko, 1990; Kim \& Mueller, 1978), com rotação varimax. Após um processo de depuração destinado a obter uma estrutura factorial clara, foi extraída uma solução de seis factores, assim designados:

O factor 1 foi denominado "sensibilidade emocional". Os 13 itens que o saturam mais fortemente são de três tipos: (1) atenção às emoções próprias; (2) sensibilidade às emoções dos outros; (3) e autocontrolo perante as críticas dos outros. Engloba itens presentes em categorias como a facilitação emocional do pensamento (Tapia, 2001), a percepção e expressão de emoções (Mayer e Salovey, 1997) e a autoconsciência (Boyatzis et al., 2000).

O factor 2 foi apelidado "empatia", pois incorpora sete itens relativos ao contágio emocional e à "sintonia" do indivíduo com as pessoas com quem se relaciona. Corresponde, em grande medida, às categorias "orientação empática" e "entusiasmo responsivo" (do original "responsive joy") ambas presentes no International Personality Item Pool (2001). Também se sobrepõe parcialmente com a categoria "regulação reflexiva das emoções" (Tapia, 2001). Mayer e Salovey, no factor "percepção e expressão emocional", também incluem a capacidades dos indivíduos reagirem empaticamente a estímulos presentes nos estados físicos e psicológicos dos outros (Salovey et al., 2002).

O factor 3 foi designado "compreensão das emoções próprias", pois os seis itens que mais o saturam respeitam ao grau em que o indivíduo compreende os seus sentimentos e emoções, assim como as suas respectivas causas. Estes processos cognitivos são mais complexos do que os relativos à subcategoria "atenção às emoções próprias" (factor 1), pois implicam compreensão e não apenas atenção ou identificação. Esta dimensão denota algumas relações com categorias identificadas em outros trabalhos, de que se ilustram: (a) percepção, avaliação e expressão de emoções (Tapia, 2001); (b) avaliação das emoções próprias (Wong \& Law, 2002); (c) e compreensão emocional (Mayer \& Salovey, 1997).

O factor 4 foi denominado "auto-encorajamento". Abarca seis itens relativos ao uso das emoções. Abarca itens relativos ao uso das emoções. Abarca a capacidade de um indivíduo se automotivar e encorajar. Uma pessoa com elevada pontuação nestes itens tem facilidade em orientar-se por objectivos e é dotada de espírito de iniciativa. O factor corresponde, 
em medida considerável, à regulação das emoções (Wong \& Law, 2002), à aplicação do conhecimento emocional (Tapia, 2001) e à autogestão (Boyatzis et al., 2000).

O factor 5 recebeu a denominação de "compreensão das emoções dos outros" (seis itens). Corresponde, em elevado grau, à dimensão "compreensão emocional" (Mayer \& Salovey, 1997) e "avaliação das emoções dos outros" (Wong \& Law, 2002).

O factor 6 foi designado "autocontrolo emocional" (quatro itens), pois diz respeito ao grau em que o indivíduo é capaz de controlar as suas emoções em situações de forte carga emocional, assim como à capacidade do indivíduo para se redireccionar e priorizar o pensamento com base em sentimentos e emoções associadas. Este tipo de capacidades está patente em categorias como a utilização das emoções (Wong \& Law, 2002), a utilização reflexiva das emoções (Tapia, 2001) e a gestão das emoções (Mayer \& Salovey, 1997).

Esta estrutura factorial denota boas propriedades psicométricas em vários domínios: (1) as saturações dos itens atinentes a cada factor são superiores a 0,50 e distanciam-se das saturações cruzadas com outros factores; (2) os alphas de Cronbach ultrapassam, invariavelmente, a barreira de 0,70 (Nunnally, 1978); (3) as seis dimensões explicam 29\% da variância da medida de satisfação com a vida, sendo especialmente preditivas as dimensões auto-encorajamento e autocontrolo emocional. Todavia, uma análise atenta sugere que alguns aprimoramentos merecem ser realizados. Mais especificamente:

O conteúdo semântico dos descritores de alguns factores parece cruzar-se com o presente em outros factores. Por exemplo, o item "procuro compreender os sentimentos da pessoa que estou a ouvir", embora sature o factor empatia, parece também integrável na dimensão "compreensão das emoções dos outros". Ainda ilustrando: o item "sou indiferente à sensibilidade dos outros", embora sature o primeiro factor, parece igualmente passível de inclusão na dimensão "empatia".

$\mathrm{O}$ instrumento não prima pela parcimónia. A elevada quantidade de itens $(n=13)$ do primeiro factor sugere a necessidade de pesquisas adicionais que permitam seleccionar os descritores mais pertinentes e/ou discernir a existência de mais do que uma dimensão no seu seio.

Esta segunda possibilidade adquire verosimilhança quando se verifica a existência de vários tipos de itens: (1) os últimos cinco respeitam ao grau em que os indivíduos são capazes de se autocontrolarem perante as críticas; (2) a maior parte dos restantes parece poder disseminar-se pelas dimensões "empatia" e "atenção/compreensão das emoções próprias". O facto de esta heterogeneidade não ter sido identificada na estrutura factorial obtida por Rego e Fernandes pode ter resultado das particularidades da 
amostra e/ou de escolhas dos investigadores numa matéria que é susceptível de interpretações diversas e de diferentes opções sobre quais os itens e os factores a reter. É objectivo da presente pesquisa testar o grau em que a estrutura factorial obtida pelos dois investigadores se reitera ou não em outras amostras. Para reforço da validação, é testado o grau em que as seis dimensões explicam os níveis de saúde-doença dos indivíduos, assim como os seus níveis de satisfação com a vida.

\section{Método}

\section{Primeira amostra}

Foram inquiridas duas amostras. A primeira integra 152 estudantes da Universidade de Aveiro, frequentando diversos cursos de Licenciatura (e.g., Ensino de Físico-Química, Economia, Gestão, Biologia, Gestão e Planeamento em Turismo, Ensino de Matemática, Ensino de Português-Inglês). 113 são do sexo feminino. A idade média cifra-se em 21,8 anos. Os inquiridos foram convidados a responder ao questionário de medida da IE constituído pelos 41 itens remanescentes do estudo de Rego e Fernandes. Usou-se a mesma escala tipo Likert de sete pontos antes citada. Os indivíduos foram ainda confrontados com sete itens destinados a medir os níveis de saúde-doença física: (1) Tenho tido dificuldades em dormir; (2) Tenho tido dores de cabeça; (3) Tenho sentido um cansaço generalizado; (4) Tenho sentido formigueiros ou dores agudas em certas partes do corpo; (5) Tenho sentido perda de apetite sexual; (6) De manhã, não tenho sentido vontade de me levantar; (7) Tenho sentido tonturas. Estes descritores foram extraídos em Evers e seus colaboradores (2000), que os adaptaram a partir do Occupational Stress Indicator (Cooper et al., 1988). Aos inquiridos foi requerido que assinalassem, mediante uma escala de sete pontos (1: nunca; [...]; 7: sempre), a frequência com que tinham experimentado estes sintomas nos últimos três meses.

Os dados foram submetidos a uma análise factorial (Principal Axis Factoring), com rotação oblimin. Levou-se a cabo um processo iterativo destinado a obter uma estrutura factorial clara. Com esse intuito, foram seleccionados, para cada factor, os itens com saturações superiores a 0,50. Foram removidos os descritores cujas saturações eram superiores a 0,40 em mais do que um factor. Deste processo resultou uma estrutura dimensional de seis factores (KMO: 0,79; teste de esfericidade de Bartlett: 1303,$83 ; \mathrm{p}=0,000 ; 51,2 \%$ de variância explicada), contendo 23 itens. Foram calculadas as consistências internas (alphas de Cronbach) das escalas 
respectivas. As cotações nas seis dimensões foram depois submetidas a uma análise de regressão tendo em vista testar o seu poder explicativo para a medida de saúde-doença física (alpha $=0,72)$.

\section{Segunda amostra}

A segunda amostra contempla 301 indivíduos, dos quais 216 são alunos de vários cursos de Licenciatura e de Mestrado da Universidade de Aveiro (idade média: 27,1 anos; desvio-padrão: 10,2 anos), e 85 são colaboradores de uma grande empresa industrial da região centro de Portugal (idade média: 34,3 anos; desvio-padrão: 10,4 anos; $45 \%$ do sexo feminino). A inteligência emocional foi medida através dos 23 itens remanescentes da análise factorial incidente sobre os dados do primeiro estudo, tendo sido usada a mesma escala de sete pontos antes aludida (1: "não se aplica rigorosamente nada a mim"; [...]; 7: "aplica-se completamente a mim"). Os indivíduos foram ainda convidados a assinalar o grau em que se lhes aplicavam cinco afirmações relativas à satisfação com a vida em geral: (1) Em muitos aspectos, a minha vida aproxima-se do meu ideal; (2) As condições da minha vida são excelentes; (3) Estou satisfeito com a minha vida; (4) Até agora, consegui alcançar as coisas mais importantes que quero na vida; (5) Se pudesse voltar atrás na minha vida, não mudaria quase nada. Estes itens foram adaptados da Satisfaction with Life Scale desenvolvida e validada por Diener e seus colaboradores (1985). Foi usada a mesma escala tipo Likert de sete pontos antes referida. O alpha de Cronbach situa-se em 0,84.

Os dados referentes à IE foram submetidos a uma análise factorial confirmatória (método da máxima verosimilhança; Byrne, 1998), tendo sido testado o modelo de seis factores antes extraído. Os índices de ajustamento revelaram-se relativamente insatisfatórios. Após terem sido removidos dois descritores à luz dos índices de modificação e dos resíduos estandardizados (Byrne, 1998), os índices de ajustamento do modelo melhoraram significativamente. Mais especificamente: (a) o rácio qui-quadrado/graus de liberdade passou de 2,8 para 1,9; (b) o RMSEA, de 0,08 para 0.06; (c) o GFI, de 0,85 para 0,90; (d) o AGFI, de 0,81 para 0,87; (e) o CFI, de 0,84 para 0,92 ; (f) o IFI, de 0,84 para 0,93 ; (g) o RFI, de 0,74 para 0,83 . As seis variáveis foram depois submetidas a uma análise de regressão, testando-se o seu poder explicativo para a variável "satisfação com a vida". 
Quadro 1: Análise factorial, após rotação oblimin

\begin{tabular}{|c|c|c|c|c|c|c|}
\hline & $\begin{array}{l}\text { Factor } 1 \\
\text { Empatia }\end{array}$ & $\begin{array}{c}\text { Factor } 2 \\
\text { Auto- } \\
\text { controlo } \\
\text { perante } \\
\text { as } \\
\text { críticas }\end{array}$ & $\begin{array}{c}\text { Factor } 3 \\
\text { Auto- } \\
\text { controlo } \\
\text { emo- } \\
\text { cional }\end{array}$ & $\begin{array}{c}\text { Factor } 4 \\
\text { Auto- } \\
\text { encora- } \\
\text { jamento } \\
\text { (uso das } \\
\text { emo- } \\
\text { ções) }\end{array}$ & $\begin{array}{c}\text { Factor } 5 \\
\text { Com- } \\
\text { preen- } \\
\text { são das } \\
\text { emoções } \\
\text { pró- } \\
\text { prias }\end{array}$ & $\begin{array}{c}\text { Factor } 6 \\
\text { Com- } \\
\text { preen- } \\
\text { são das } \\
\text { emoções } \\
\text { dos } \\
\text { outros }\end{array}$ \\
\hline $\begin{array}{l}\text { Quando algum amigo meu } \\
\text { ganha um prémio, sinto-me } \\
\text { feliz por ele }\end{array}$ & 0.84 & $-0,25$ & $-0,02$ & $-0,24$ & $-0,30$ & $-0,14$ \\
\hline $\begin{array}{l}\text { Sou indiferente à felicidade } \\
\text { dos outros (i) }\end{array}$ & $-0,63$ & 0,30 & $-0,01$ & 0,18 & 0,31 & 0,12 \\
\hline $\begin{array}{l}\text { Sinto-me bem quando um } \\
\text { amigo meu recebe um elogio }\end{array}$ & 0,52 & $-0,33$ & $-0,27$ & $-0,25$ & $-0,22$ & $-0,36$ \\
\hline $\begin{array}{l}\text { Vivo os problemas dos meus } \\
\text { amigos como se fossem os } \\
\text { meus problemas }\end{array}$ & 0,52 & $-0,21$ & $-0,11$ & $-0,18$ & $-0,19$ & $-0,23$ \\
\hline $\begin{array}{l}\text { Fico irritado quando me } \\
\text { criticam - mesmo sabendo } \\
\text { que as outras pessoas têm } \\
\text { razão (i) }\end{array}$ & 0,40 & $-0,76$ & $-0,07$ & $-0,22$ & $-0,19$ & $-0,11$ \\
\hline $\begin{array}{l}\text { É difícil para mim aceitar } \\
\text { uma crítica (i) }\end{array}$ & 0,26 & $-0,70$ & $-0,12$ & $-0,34$ & $-0,12$ & $-0,14$ \\
\hline $\begin{array}{l}\text { Não lido bem com as críticas } \\
\text { que me fazem (i) }\end{array}$ & 0,16 & $-0,67$ & $-0,07$ & $-0,01$ & $-0,02$ & $-0,13$ \\
\hline $\begin{array}{l}\text { Tenho dificuldade em } \\
\text { conversar com pessoas que } \\
\text { não partilham os pontos de } \\
\text { vista idênticos aos meus(i) }\end{array}$ & 0,26 & $-0,65$ & $-0,26$ & $-0,11$ & $-0,26$ & $-0,36$ \\
\hline $\begin{array}{l}\text { Quando sou derrotado num } \\
\text { jogo, perco o controlo (i) }\end{array}$ & 0,22 & $-0,52$ & 0,06 & $-0,22$ & $-0,19$ & $-0,13$ \\
\hline $\begin{array}{l}\text { Consigo permanecer calmo, } \\
\text { mesmo quando os outros } \\
\text { ficam zangados }\end{array}$ & 0,05 & 0,03 & 0,82 & $-0,04$ & 0,10 & 0,08 \\
\hline $\begin{array}{l}\text { Reajo com calma quando } \\
\text { estou sob tensão }\end{array}$ & $-0,27$ & 0,19 & 0,66 & 0,17 & 0,35 & 0,19 \\
\hline $\begin{array}{l}\text { Sou realmente capaz de } \\
\text { controlar as minhas próprias } \\
\text { emoções }\end{array}$ & $-0,01$ & 0,04 & 0,56 & 0,26 & 0,34 & 0,32 \\
\hline $\begin{array}{l}\text { Dou o melhor de mim para } \\
\text { alcançar os objectivos a que } \\
\text { me propus }\end{array}$ & $-0,20$ & 0,21 & 0,11 & 0,75 & 0,27 & 0,36 \\
\hline
\end{tabular}




\begin{tabular}{|c|c|c|c|c|c|c|}
\hline & $\begin{array}{l}\text { Factor } 1 \\
\text { Empatia }\end{array}$ & $\begin{array}{l}\text { Factor } 2 \\
\text { Auto- } \\
\text { controlo } \\
\text { perante } \\
\text { as } \\
\text { críticas }\end{array}$ & $\begin{array}{c}\text { Factor } 3 \\
\text { Auto- } \\
\text { controlo } \\
\text { emo- } \\
\text { cional }\end{array}$ & $\begin{array}{c}\text { Factor } 4 \\
\text { Auto- } \\
\text { encora- } \\
\text { jamento } \\
\text { (uso das } \\
\text { emo- } \\
\text { ções) }\end{array}$ & $\begin{array}{c}\text { Factor } 5 \\
\text { Com- } \\
\text { preen- } \\
\text { são das } \\
\text { emoções } \\
\text { pró- } \\
\text { prias }\end{array}$ & $\begin{array}{c}\text { Factor } 6 \\
\text { Com- } \\
\text { preen- } \\
\text { são das } \\
\text { emoções } \\
\text { dos } \\
\text { outros }\end{array}$ \\
\hline $\begin{array}{l}\text { Normalmente, encorajo-me a } \\
\text { mim próprio para dar o meu } \\
\text { melhor }\end{array}$ & $-0,24$ & 0,37 & $-0,01$ & $\mathbf{0 , 7 3}$ & 0,37 & 0,19 \\
\hline $\begin{array}{l}\text { De uma forma geral, costumo } \\
\text { estabelecer objectivos para } \\
\text { mim próprio }\end{array}$ & $-0,26$ & 0,13 & 0,13 & 0,69 & 0,26 & 0,06 \\
\hline Sei bem o que sinto & $-0,24$ & 0,12 & 0,22 & 0,29 & $\mathbf{0 , 8 7}$ & 0,11 \\
\hline $\begin{array}{l}\text { De uma forma geral, tenho } \\
\text { consciência dos meus } \\
\text { sentimentos }\end{array}$ & $-0,36$ & 0,13 & 0,10 & 0,33 & $\mathbf{0 , 7 3}$ & 0,18 \\
\hline $\begin{array}{l}\text { Compreendo as causas das } \\
\text { minhas emoções }\end{array}$ & $-0,27$ & 0,15 & 0,26 & 0,18 & $\mathbf{0 , 7 0}$ & 0,37 \\
\hline $\begin{array}{l}\text { Compreendo os meus } \\
\text { sentimentos e emoções }\end{array}$ & $-0,26$ & 0,23 & 0,25 & 0,20 & 0,67 & 0,29 \\
\hline $\begin{array}{l}\text { Quando estou triste, sei quais } \\
\text { são os motivos }\end{array}$ & $-0,02$ & 0,11 & 0,23 & 0,33 & 0,56 & 0,27 \\
\hline $\begin{array}{l}\text { Procuro compreender os } \\
\text { sentimentos da pessoa que } \\
\text { estou a ouvir }\end{array}$ & $-0,39$ & 0,30 & 0,11 & 0,13 & 0,25 & $\mathbf{0 , 7 7}$ \\
\hline $\begin{array}{l}\text { Consigo compreender as } \\
\text { emoções e sentimentos dos } \\
\text { meus amigos vendo os seus } \\
\text { comportamentos }\end{array}$ & $-0,07$ & 0,08 & 0,20 & 0,26 & 0,28 & 0,56 \\
\hline $\begin{array}{l}\text { Empenho-me em } \\
\text { compreender os pontos de } \\
\text { vista das outras pessoas }\end{array}$ & $-0,37$ & 0,37 & 0,14 & 0,27 & 0,32 & $\mathbf{0 , 5 1}$ \\
\hline Variância explicada (\%) & 24,0 & 8,6 & 6,2 & 5,0 & 4,1 & 3,8 \\
\hline Alphas de Cronbach & 0,73 & 0,79 & 0,70 & 0,77 & 0,82 & 0,67 \\
\hline
\end{tabular}

(i) Para calcular a IE, as cotações nestes itens foram invertidas

\section{Resultados}

O Quadro 1 expõe os resultados da análise factorial. O primeiro factor pode ser denominado "empatia". Integra três itens que Rego e Fernandes obtiveram para medir a dimensão homónima, ao que acresce um 
descritor que na pesquisa desses investigadores se inseria no factor "sensibilidade emocional". O segundo factor reflecte o autocontrolo perante as críticas. É constituído pelos últimos cinco itens inseridos no factor "sensibilidade emocional" colhido na pesquisa de Rego e Fernandes. O terceiro factor reflecte o autocontrolo emocional, apenas não sendo coincidente com o factor homónimo extraído por Rego e Fernandes pelo facto de dois itens terem sido aqui retirados. O factor 4 representa o auto-encorajamento que Rego e Fernandes já haviam obtido, apenas divergindo no facto de três itens aí presentes terem sido aqui removidos. $\mathrm{O}$ quinto factor integra itens representativos da compreensão das emoções próprias. Coincide com o factor extraído na pesquisa de Rego e Fernandes, exceptuando um item que foi removido na presente pesquisa. $\mathrm{O}$ último factor representa a compreensão das emoções dos outros, sendo constituído por um item que saturava a dimensão homónima de Rego e Fernandes e por dois itens que se inseriam na dimensão "empatia" que esses pesquisadores extraíram. Os alphas de Cronbach tendem a superar o patamar de 0,70 sugerido por Nunnally (1978), facto estatístico que apenas não ocorre no último factor.

O Quadro 2 reporta-se aos resultados da análise factorial confirmatória aplicada aos dados de IE da segunda amostra. Genericamente, os índices de ajustamento são satisfatórios e apenas um Lambda se situa abaixo de 0,50. Apenas o alpha de Cronbach referente à última dimensão se situa abaixo de 0,70 , embora num patamar próximo. O teste do modelo para cada sexo gera resultados muito similares. Por exemplo, em ambos os casos, apenas o Lambda referente a um dos itens da última dimensão se cifra abaixo de 0,50. Acresce que os índices de ajustamento do modelo são satisfatórios para as duas subamostras. Mais especificamente, o RMSEA, o GFI, o AGFI, o CFI, o IFI e o RFI são, com esta sequência, os seguintes: (a) Sexo masculino: 0,01, 0,90, 0,87, 1,0,1,0 e 0,83; (b) sexo feminino: $0,03,0,90,0,87,0,97,0,97$ e 0,83 .

O Quadro 3 expõe as médias, desvios-padrão e correlações entre variáveis, contemplando evidência empírica referente às duas amostras. Em geral, as cotações em IE são relativamente elevadas (cerca de 5 pontos em 7), sendo mais fracas as respeitantes ao autocontrolo emocional. Com parcas excepções, as dimensões de IE correlacionam-se significativa e positivamente entre si, embora os coeficientes possam ser considerados modestos ou moderados. As dimensões de IE correlacionam-se positivamente com o indicador de saúde, apenas não sendo significativo o coeficiente relativo à compreensão das emoções dos outros. Todas as dimensões se correlacionam positivamente com a satisfação com a vida. Parece, por conseguinte, que a saúde e a satisfação com a vida são mais vigorosas entre os indivíduos emocionalmente mais inteligentes. 
Quadro 2: Resultados da análise factorial confirmatória (solução completamente estandardizada)

\section{Compreensão das emoções próprias}

Compreendo os meus sentimentos e emoções.

Sei bem o que sinto.

Quando estou triste, sei quais são os motivos.

Compreendo as causas das minhas emoções.

Tenho dificuldade em conversar com pessoas que não partilham os pontos de vista idênticos aos meus. (i)

Fico irritado quando me criticam - mesmo sabendo que as outras pessoas têm razão. (i)

Não lido bem com as críticas que me fazem. (i)

É difícil para mim aceitar uma crítica. (i)

Quando sou derrotado num jogo, perco o controlo. (i)

Normalmente, encorajo-me a mim próprio para dar o meu melhor.

Dou o melhor de mim para alcançar os objectivos a que me propus.

De uma forma geral, costumo estabelecer objectivos para mim próprio.

Reajo com calma quando estou sob tensão.

Consigo permanecer calmo, mesmo quando os outros ficam zangados. $\quad 0,74$

Sou realmente capaz de controlar as minhas próprias emoções. $\quad 0,62$

Empatia

Quando algum amigo meu ganha um prémio, sinto-me feliz por ele. $\quad 0,85$

Sinto-me bem quando um amigo meu recebe um elogio. $\quad 0,84$

Vivo os problemas dos meus amigos como se fossem os meus problemas. $\quad 0,50$

\section{Compreensão das emoções dos outros}

Consigo compreender as emoções e sentimentos dos meus amigos vendo os seus comportamentos.

Procuro compreender os sentimentos da pessoa que estou a ouvir.

0,68

\begin{tabular}{rr} 
Qui-quadrado/Graus de liberdade & 1,9 \\
Root mean square root of approximation & 0,06 \\
Goodness of fit index & 0,90 \\
Adjusted goodness of fit index & 0,87 \\
Comparative fit index & 0,92 \\
Incremental fit index & 0,93 \\
Relative fit index & 0,83 \\
\hline
\end{tabular}

\# Entre parêntesis: alphas de Cronbach

(i) item invertido 
Quadro 3: Médias, desvios-padrão e correlações entre variáveis para as duas amostras (\#)

\begin{tabular}{|c|c|c|c|c|c|c|c|c|c|c|}
\hline & & Média & DP & 1 & 2 & 3 & 4 & 5 & 6 & 7 \\
\hline \multirow{2}{*}{1.} & \multirow{2}{*}{$\begin{array}{l}\text { Compreensão } \\
\text { das emoções } \\
\text { próprias }\end{array}$} & 5,1 & 0,9 & - & & & & & & \\
\hline & & 5,0 & 0,9 & & & & & & & \\
\hline \multirow[t]{2}{*}{2.} & Autocontrolo & 5,2 & 0,8 & $0,23 * *$ & - & & & & & \\
\hline & $\begin{array}{l}\text { perante as } \\
\text { críticas }\end{array}$ & 5,0 & 1,0 & $0,11^{*}$ & & & & & & \\
\hline \multirow[t]{2}{*}{3.} & Auto- & 5,5 & 0,9 & $0,36 * * *$ & $0,31 * * *$ & - & & & & \\
\hline & encorajamento & 5,4 & 0,9 & $0,44 * * *$ & $0,21 * * *$ & & & & & \\
\hline \multirow[t]{2}{*}{4.} & Autocontrolo & 4,0 & 1,1 & $0,35 * * *$ & $0,16^{*}$ & 0,14 & - & & & \\
\hline & emocional & 4,2 & 0,9 & $0,36 * * *$ & $-0,05$ & $0,27 * * *$ & & & & \\
\hline \multirow[t]{2}{*}{5.} & Empatia & 5,6 & 0,8 & $0,35 * * *$ & $0,38 * * *$ & $0,33 * * *$ & $0,17^{*}$ & - & & \\
\hline & & 5,3 & 0,9 & $0,16^{* *}$ & $0,25 * * *$ & $0,33 * * *$ & 0,05 & & & \\
\hline \multirow[t]{2}{*}{6.} & Compreensão & 5,4 & 0,7 & $0,38 * * *$ & $0,39 * * *$ & $0,33 * * *$ & $0,23 * *$ & $0,40 * * *$ & - & \\
\hline & $\begin{array}{l}\text { das emoções } \\
\text { dos outros }\end{array}$ & 5,2 & 0,7 & $0,29 * * *$ & $0,24 * * *$ & $0,42 * * *$ & $0,14 *$ & $0,64 * * *$ & & \\
\hline \multirow[t]{2}{*}{7.} & Saúde física & 4,8 & 0,8 & $0,30 * * *$ & $0,25 * *$ & $0,26 * * *$ & $0,29 * * *$ & $0,18^{* *}$ & 0,14 & - \\
\hline & & n.a. & n.a. & n.a. & n.a. & n.a. & n.a. & n.a. & n.a. & \\
\hline \multirow[t]{2}{*}{8.} & Satisfação com & n.a & n.a. & n.a. & n.a. & n.a. & n.a. & n.a. & n.a. & n.a. \\
\hline & & 4,7 & 1,0 & $0,32 * * *$ & $0,16^{* *}$ & $0,50 * * *$ & $0,24 * * *$ & $0,22 * * *$ & $0,24 * * *$ & n.a. \\
\hline
\end{tabular}

$* \mathrm{p}<0,05 ; * * \mathrm{p}<0,01 ; * * * \mathrm{p}<=0,001$

\# A primeira linha representa os dados da $1 .^{\mathrm{a}}$ amostra; a segunda reporta-se aos dados da $2 .^{\mathrm{a}}$.

n.a. - não aplicável

Para se testar o poder preditivo da IE para a saúde, uma análise de regressão foi efectuada. Os resultados estão contemplados no Quadro 4, apontando para $14 \%$ de variância explicada. As variáveis mais pertinentes são a compreensão das emoções próprias, o autocontrolo perante as críticas e o autocontrolo emocional. Idêntico procedimento estatístico foi usado para explicar a satisfação com a vida, atingindo a variância explicada $26 \%$ e sendo a dimensão mais pertinente o auto-encorajamento. A consideração das duas subamostras sugere que, embora o auto-encorajamento mantenha a predominância explicativa em ambas, algumas diferenças podem ser identificadas. Por exemplo: (a) o autocontrolo perante as críticas explica a satisfação dos empregados da empresa industrial, mas não a dos estudantes; (b) padrão simétrico se detecta na compreensão das emoções próprias; (c) a variância explicada é maior na amostra de estudantes. Como 
nota esclarecedora, acrescente-se que, na amostra de membros organizacionais, os Betas de duas dimensões de IE são negativos. O dado causa alguma surpresa pelo facto de as correlações (Quadro 3) entre essas duas variáveis e a satisfação serem significativamente positivas. Há razões para presumir que essa evidência resulta da interacção entre as variáveis de IE. Por exemplo: (a) quando se acrescenta à regressão o produto das dimensões "compreensão das emoções próprias" e "empatia", os respectivos $B e$ tas tornam-se significativamente positivos e a variância explicada da satisfação passa de 0,23 para 0,27; (b) quando a compreensão das emoções próprias é fraca (inferior à média), o autocontrolo perante as críticas não explica a satisfação, mas explica $12 \%$ da sua variância quando a compreensão das emoções próprias é forte; (c) a variância de satisfação explicada pelo auto-encorajamento passa de $11 \%$ para $20 \%$ quando a compreensão das emoções próprias passa de fraca a forte; (d) genericamente, a forte compreensão das emoções próprias (o mesmo sucedendo com a forte empatia) produz os mais elevados níveis de satisfação quando está associada com elevadas cotações nas restantes dimensões. Estes dados requerem, todavia, algumas cautelas interpretativas devido à pequena dimensão da subamostra $(\mathrm{n}=85)$.

Quadro 4: Regressões - Poder explicativo da IE para a saúde e a satisfação com a vida (Betas)

\begin{tabular}{|c|c|c|c|c|}
\hline \multirow[b]{2}{*}{ Preditores } & \multirow[b]{2}{*}{$\begin{array}{c}\text { Saúde } \\
\left(1 .^{\text {a }} \text { amos- }\right. \\
\text { tra) }\end{array}$} & \multicolumn{3}{|c|}{$\begin{array}{c}\text { Satisfação com a vida } \\
\left(2 .^{a} \text { amostra }\right)\end{array}$} \\
\hline & & $\begin{array}{l}\text { Estudantes } \\
\text { (A) }\end{array}$ & $\begin{array}{c}\text { Membros da } \\
\text { organização } \\
\text { industrial (B) }\end{array}$ & $\begin{array}{c}\text { Total } \\
(\mathrm{A}+\mathrm{B})\end{array}$ \\
\hline Compreensão das emoções próprias & $0,16^{*}$ & $0,19 * *$ & $-0,20$ & 0,10 \\
\hline Autocontrolo perante as críticas & $0,16^{*}$ & 0,05 & $0,22 *$ & 0,06 \\
\hline Auto-encorajamento & 0,15 & $0,40 * * *$ & $0,32 *$ & $0,41 * * *$ \\
\hline Autocontrolo emocional & $0,20 *$ & 0,09 & 0,15 & 0,10 \\
\hline Empatia & 0,01 & 0,12 & $-0,14$ & 0,07 \\
\hline Compreensão das emoções dos outros & $-0,08$ & $-0,07$ & 0,25 & $-0,03$ \\
\hline $\mathbf{F}$ & $5,20 * * *$ & $16,71 * * *$ & $5,07 * * *$ & $18,69 * * *$ \\
\hline $\mathbf{R}^{2}$ ajustado & 0,14 & 0,31 & 0,23 & 0,26 \\
\hline
\end{tabular}




\section{Discussão}

O primeiro indicador relevante extraído dos dados expostos é o de que, globalmente, o instrumento de medida denota boas propriedades psicométricas. Primeiro, o modelo factorial é bastante claro. Segundo, as consistências internas são geralmente satisfatórias, com excepção da referente ao último factor. Todavia, mesmo este se aproxima do patamar desejável. Terceiro, as diversas dimensões correlacionam-se significativamente entre si, o que reforça a ideia de que estamos perante dimensões de um mesmo constructo. Mas essas correlações não são suficientemente elevadas para suscitar problemas de multicolinearidade e, por conseguinte, para hipotecar a valia da partição dimensional. Quarto, as seis dimensões de IE explicam $14 \%$ da variância da medida de saúde e $26 \%$ da variância da satisfação com a vida. Esta evidência pode sugerir que os indivíduos emocionalmente mais inteligentes se ajustam melhor à envolvente externa e lidam melhor com as contingências da vida, criam e desenvolvem redes de relações interpessoais que lhes permitem lidar mais facilmente com fontes de stress, estabelecem relações mais saudáveis com os outros (Slaski e Cartwright, 2002, 2003). Parafraseando Slaski e Cartwright (2003), "as emoções servem para canalizar recursos para matérias que, de algum modo, possam ameaçar a integridade do indivíduo, seja ela a física, a social ou a psicológica. As emoções são também adaptativas, pois protegem o indivíduo dos danos físicos, facilitam a manutenção da auto-identidade em situações sociais e guiam o indivíduo na realização de tarefas e na prossecução de objectivos" (p. 234).

O segundo elemento pertinente é o que concerne ao facto de as dimensões factoriais extraídas poderem ser identificadas na literatura, seja autonomamente ou inseridas em outras dimensões. E embora o seu conteúdo ultrapasse as quatro dimensões presentes no modelo de competências de Mayer, Salovey e seus colaboradores, é indubitável a sua proximidade. Por exemplo: (a) o autocontrolo emocional do constructo compagina-se com a regulação das emoções; (b) os dois factores relativos à compreensão das emoções (próprias e dos outros) são consistentes com a compreensão das emoções; (c) o auto-encorajamento denota sobreposições com o uso das emoções; (d) a própria empatia, embora não possa ser considerada, em sentido estrito, uma competência mental, contém alguns laivos de compreensão de emoções que a abeiram dessa competência presente no esquema de Mayer, Salovey e seus colaboradores.

$\mathrm{O}$ terceiro aspecto relevante da presente pesquisa é que, relativamente à extraída por Rego e Fernandes, esta dimensionalização é mais clara do ponto de vista dos conteúdos semânticos de cada factor. Por exemplo, tal como se aludiu anteriormente, a dimensão sensibilidade emo- 
cional integrava uma grande quantidade de itens, cuja natureza era bastante diversa. O que aqui se verifica é que dele emerge uma dimensão específica denominada autocontrolo perante as críticas, sendo os restantes itens removidos ou afectos a outras dimensões.

Parece, por conseguinte, ter-se progredido na validação do constructo. Porque o tema denota muito exígua presença na literatura publicada em língua portuguesa, a presente investigação representa, pois, um contributo adicional meritório para que outros estudos possam ser levados a cabo com o recurso a um instrumento com boas propriedades psicométricas. A validação das escalas na população portuguesa deixa em aberto a necessidade de estudos serem levados a cabo noutras culturas. Essa é a via apropriada para se testar a validade transcultural do modelo e do instrumento de medida dele emergente.

Algumas limitações da pesquisa e pistas para investigação futura merecem, agora, atenção. Primeira: apenas duas variáveis dependentes foram aqui consideradas. Variáveis como o sucesso académico, a eficácia de liderança, o sucesso profissional, o stress, o bem-estar afectivo são exemplos de domínios cujo estudo outros investigadores poderão aprofundar com base no constructo aqui explanado.

Segunda: a dimensão da primeira amostra é reduzida. O ratio de 152 indivíduos para 41 itens, embora ultrapasse o critério de 3:1 que alguns autores sugerem, não cumpre critérios mais rigorosos apontados por outros investigadores (Kline, 1994). E, embora a estrutura dimensional obtida seja replicada na segunda amostra (de maior dimensão e com o recurso a uma técnica estatística mais exigente), teria sido psicometricamente mais recomendável colher uma amostra de maior dimensão. A nossa sugestão é, pois, a de que outros investigadores tomem em mãos o instrumento de medida sugerido por Rego e Fernandes e o apliquem numa amostra de maiores dimensões.

A terceira limitação relaciona-se com a peculiaridade das amostras, que são constituídas exclusiva (primeira amostra) ou maioritariamente (segunda amostra) por estudantes. Acresce a predominância de indivíduos do sexo feminino. Embora tal pareça não ter repercussões na estrutura dimensional, pode conduzir a alguns enviesamentos (como abaixo se explanará). Por conseguinte, seria desejável que mais estudos fossem realizados com indivíduos de origens sociais, económicas, culturais e de género distintas das consagradas no trabalho aqui apresentado. Note-se que tão ou mais relevante do que discutir se as amostras por nós inquiridas representam a população portuguesa é saber se as relações estatísticas entre a IE e as variáveis dependentes são contingentes. Esta representa a quarta limitação da pesquisa e é um factor indutor da necessidade de se testar a validade preditiva em diferentes amostras. Evidência empírica colhida na nossa 
pesquisa confere verosimilhança a esta hipótese. Por exemplo, o autocontrolo perante as críticas explica a satisfação dos membros da organização industrial, mas não a dos estudantes (Quadro 4). A consideração separada dos indivíduos de cada sexo também sugere a contingencialidade. Por exemplo: (a) na amostra de estudantes da segunda amostra, o autocontrolo emocional explica a satisfação dos homens mas não a das mulheres. $\mathrm{O}$ inverso ocorre com a compreensão das emoções próprias; (b) na primeira amostra, a compreensão das emoções próprias também explica o nível de saúde das alunas, mas não o dos seus congéneres masculinos; (c) em ambas as amostras, as variâncias explicadas são mais elevadas entre os indivíduos do sexo feminino do que entre os do sexo masculino. Por conseguinte, pode suceder que as competências de IE mais pertinentes sejam diferentes consoante o sexo, a ocupação, a idade e outros factores de contingência.

Quinta limitação: a consistência interna das escalas de medida da última dimensão é inferior ao desejável. Embora se situe em patamar próximo, a necessidade de aprimoramento parece inquestionável.

Sexta limitação: os conteúdos semânticos dos itens de algumas dimensões merecem atenção especial em futuras investigações. Por exemplo, a dimensão empatia ficou subsumida a três itens na fase confirmatória do estudo, sendo todos focalizados na relação do indivíduo com os seus amigos. Do nosso ponto de vista, seria desejável que outros focos fossem considerados em futuras investigações. Pode suceder que os itens meçam mais os comportamentos sociais de reciprocidade próprios da relação de amigos do que, propriamente, a competência da empatia nas relações sociais em geral.

Sétima limitação: as variáveis dependentes e independentes foram colhidas simultaneamente e na mesma fonte. Daqui podem resultar riscos de variância do método comum (Podsakoff \& Organ, 1986) que estudos posteriores poderão evitar. Uma das vias alternativas é o recurso a estudos longitudinais, sendo os dados referentes às variáveis dependentes e independentes colhidos em momentos temporais distanciados. Outra via é a obtenção, para as variáveis dependentes, de dados clínicos objectivos - e não os declarados pelos inquiridos. A sétima limitação está relacionada com esta que acaba de ser enunciada, embora não se esgote nela: não é possível inferir relações de causalidade peremptória entre a IE e as variáveis dependentes. Uma boa ilustração pode ser aduzida a propósito do auto-encorajamento. Ainda que seja verosímil que as pessoas mais auto-encorajadas ou automotivadas experimentem mais satisfação com a vida (porque, por exemplo, conseguem melhores resultados do seu empenhamento no trabalho e/ou na vida académica), também é plausível o argumento segundo o qual a satisfação com a vida torna o indivíduo mais automotivado. 
A última menção recai sobre o método de medição da IE: a autodescrição. Ele assenta na premissa de que os indivíduos detêm capacidades de auto-análise e de autoconhecimento - mas há razões para presumir que algumas pessoas possam ter um autoconceito desajustado. No limite, e a título de exemplo, um indivíduo com fraco conhecimento de si próprio (i.e., com fraca IE nesse plano) pode descrever-se muito positivamente, isto é, com elevada IE nesse domínio! Acresce que algumas respostas autodescritivas podem ser enviesadas pela desejabilidade social. Por exemplo, uma pessoa pode declarar que se "preocupa com um amigo que está doente", não porque realmente tal ocorra, mas porque esse é um valor social predominante que ele entende repercutir na resposta. Deve notar-se, todavia, que os outros métodos de medição também denotam limitações. Por conseguinte, uma via apropriada para testar a validade do presente instrumento de medida consiste em comparar os seus poderes preditivos com os produzidos por outros métodos.

Em suma: pesem embora as diversas limitações, o presente trabalho contribui para compreender a dimensionalização da IE e operacionalizar um constructo ainda em fase de adolescência científica. Representa um passo adicional ao já dado por diversos investigadores, contribuindo para que novas investigações sejam realizadas (nomeadamente em Portugal) e se compreenda melhor a relevância da IE para as múltiplas facetas da vida pessoal, familiar, social e profissional dos indivíduos. São necessárias, todavia, pesquisas posteriores que aprofundem o estudo da estrutura dimensional do constructo e da sua validade preditiva.

\section{Referências}

Barling, J., Slater, F., \& Kelloway, E. (2000). Transformational leadership and emotional intelligence: An exploratory study. The Leadership and Organizational Development Journal, 21, 157-161.

Bar-On, R. (1996). The emotional quotient inventory (EQ-i): A test of emotional intelligence. Toronto: Multi-Health Systems.

Bar-On, R. (1997). The emotional quotient inventory (EQ-i): Technical manual. Toronto: Multi-Health Systems.

Barsade, S. (2002). The ripple effect: Emotional contagion and its influence on group behavior. Administrative Science Quarterly, 47, 644-675.

Bechara, A., Tranel, D. \& Damásio, A. (2000). Poor judgment in spite of high intellect: Neurological evidence for emotional intelligence. In R. Bar-On \& J. Parker (Eds.), The handbook of emotional intelligence: Theory, development, assessment, and application at home, school, and in the workplace (pp. 192-214). San Francisco: Jossey-Bass. 
Bobko, P. (1990). Multivariate correlational analysis. In M. V. Dunnette \& L. M. Hough (Eds.), Handbook of industrial and organizational psychology (pp. 637-686). Palo Alto: Consulting Psychologists Press.

Boyatzis, R., Goleman, D. \& Hay/McBer. (1999). Emotional competence inventory. Boston: HayGroup.

Boyatzis, R., Goleman, D., \& Rhee, K.. (2000). Clustering competence in emotional intelligence: Insights from the emotional competence inventory. In J. Parker (Ed.), The handbook of emotional intelligence: Theory, development, assessment, and application at home, school, and in the workplace (pp. 343-362). San Francisco: Jossey-Bass.

Byrne, B. (1998). Structural equation modelling with lisrel, prelis and simplis. London: Erlbaum.

Caruso, D., Mayer, J., \& Salovey, P. (2001). Emotional intelligence and emotional leadership. In R. Riggio \& S. Murphy (Eds.), Multiple intelligences and leadership. Mahwah, NJ: Laurence Erlbaum Associates.

Cherniss, C. (2000, April 15). Emotional intelligence: What it is and why does it matters. Comunicação apresentada no Annual meeting of the society for industrial and organizational psychology, Nova Orleães.

Ciarrochi, J., Chan, A., \& Caputi, P. (2000). A critical evaluation of emotional intelligence construct. Personality and Individual Differences, 28, 539-561.

Cooper, C. L., Sloan, S. J., \& Williams, S. (1988). Occupational stress indicator management guide. Windsor: NFER-Nelson.

Cooper, R. (1996/1997). EQ Map. San Francisco: AIT and Essi Systems.

Cronbach, L. (1960). Essentials of psychological testing (2nd Ed.). Nova Iorque: Norton, Cooper, Golden \& Dornheim.

Davies, M., Stankov, L., \& Roberts, R. (1998). Emotional intelligence: In search of an elusive construct. Journal of Personality and Social Psychology, 75 (4), 989-1015.

Dawda, D., \& Hart, S. (2000). Assessing emotional intelligence: Reliability and validity of the Bar-On Emotional Quotient Inventory (EQ-i) in university students. Personality and Individual Differences, 28, 797-812.

Diener, E., Emmons, R., Larsen, R., \& Griffin, S. (1985). The satisfaction with life scale. Journal of Personality Assessment, 49 (1), 71-75.

Druskat, V., \& Wolff, S. (2001). Building emotional intelligence of groups. Harvard Business Review, 79 (3), 81-90.

Dulewicz, V., \& Higgs, M. (2000). Emotional intelligence - A review and evaluation study. Journal of Managerial Psychology, 15 (4), 341-372.

Evers, A., Frese, M., \& Cooper, C. L. (2000). Revisions and further developments of the occupational stress indicator: LISREL results from Dutch studies. Journal of Occupational and Organizational Psychology, 73, 221-240.

Farnham, A. (1996). Are you smart enough to keep your job? Fortune, 133 (1), 34$-36$.

Gardner, H. (1983). Frames of the mind: the theory of multiple intelligences. Nova Iorque: Basic Books. 
Gardner, H. (1993). Multiple intelligences: the theory in practice. Nova Iorque: Basic Books.

George, J. (2000). Emotions and leadership: The role of emotional intelligence. Human Relations, 53 (8), 1027-1055.

Goleman, D. (1995). Emotional Intelligence: Why can it matter more than IQ? Nova Iorque: Bantam.

Goleman, D. (1998). What makes a leader? Harvard Business Review, 76 (6), 93 -102 .

Goleman, D. (1999). Working with emotional intelligence. Londres: Bloomsbury.

Goleman, D. (2000). Leadership that gets results. Harvard Business Review, 78 (2), 78-90.

Goleman, D., Boyatzis, R., \& McKee, A. (2001). Primal Leadership: The hidden driver of great performance. Harvard Business Review, 79 (6), 42-51.

Goleman, D., Boyatzis, R., \& McKee, A. (2002). Primal leadership: Realizing the power of emotional intelligence. Boston, Massachusetts: Harvard Business Scholl Press.

Grandey, A. (2000). Emotional regulation in the workplace: A new way to conceptualize human labor. Journal of Occupational Health Psychology 5 (1), 95-110.

Harris, P. (2000). Understanding emotions. In M. Lewis \& J. Haviland-Jones (Eds.), Handbook of emotions (2nd Ed., pp. 281-292). New York: The Guildford Press.

Huy, Q. (1999). Emotional capability, emotional intelligence, and radical change. Academy of Management Review, 24 (2), 325-345.

International Personality Item Pool (2001). A scientific collaboratory for the development of advanced measures of personality traits and other individual differences. Extraído en 23/10/03 de International Personality Item Pool na World Wide Web: http://ipip.ori.org/

Johnson-Laird, P. \& Oatley, K. (2000). Cognitive and social construction emotions. In M. Lewis \& J. Haviland-Jones (Eds.), Handbook of emotions (2nd Ed., pp. 458-474). Nova Iorque: The Guildford Press.

Kaufman, A., \& Kaufman, J. (2001). Emotional intelligence as an aspect of general intelligence: What would David Wechsler say? Emotion, 1 (3), 258-264.

Kemper, T. (2000). Social models in the explanation of emotions. In M. Lewis \& J. Haviland-Jones (Eds.), Handbook of emotions (2nd Ed., pp. 45-58). Nova Iorque: The Guildford Press.

Kim, J., \& Mueller, C. (1978). Factor analysis: statistical methods and practical issues. Beverly Hills, CA: Sage.

Kline, P. (1994). An easy guide to factor analysis. London: Routledge.

Livingstone, H., Nadjiwon-Foster, M., \& Smithers, S. (2002). Emotional intelligence \& military leadership. Extraído em 14/03/2004 de Canadian Defence Academy na World Wide Web: http://www.cda.forces.gc.ca/cfli/engraph/ research/pdf/08.pdf

Mayer, J., \& Geher, G. (1996). Emotional intelligence and the identification of emotion. Intelligence, 22, 89-113. 
Mayer, J., \& Salovey, P. (1993). The intelligence of emotional intelligence. Intelligence, 17, 433-442.

Mayer, J., \& Salovey, P. (1995). Emotional intelligence and the construction and regulation of feelings. Applied and Preventive Psychology, 4, 197-208.

Mayer, J., \& Salovey, P. (1997). What is emotional intelligence. In P. Salovey \& D. Sluyter (Eds.), Emotional development and emotional intelligence: educational implications (pp. 3-34). Nova Iorque: Basic Books Inc.

Mayer, J., Salovey, P., \& Caruso, D. (1997). The emotional IQ test [CD-Rom]. Needhsam, MA: Virtual Knowledge.

Mayer, J., Caruso, D., \& Salovey (1999). Emotional intelligence meets traditional standards for an intelligence. Intelligence, 27, 267-298.

Mayer, J., Salovey, P., \& Caruso, D. (2000a). Models of emotional intelligence. In R. Sternberg (Ed.), Handbook of intelligence (pp. 396-420). Nova Iorque: Cambridge University Press.

Mayer, J., Carruso, D., \& Salovey, P. (2000b). Selecting a measure of emotional intelligence: The case for ability scales. In R. Bar-On \& J. Parker (Eds.), The Handbook of Emotional Intelligence theory, development, assessment, and application at home, school, and in the workplace (pp. 320-342). São Francisco: Jossey-Bass.

Mayer, J., Salovey, P., Caruso, D., \& Sitarenios, G. (2001). Emotional intelligence as a standard intelligence. Emotion, 1 (3), 232-242.

Megerian, L., \& Sosik, J. (1996). An affair of the heart: Emotional intelligence and transformational leadership. Journal of Leadership Studies, 3 (3), 31-48.

Mowrer, O. (1960). Learning theory and behaviour. Nova Iorque: Wiley.

Nunnally, J. C. (1978). Psychometric theory. Nova Iorque: McGraw-Hill.

Palmer, B., Donaldson, C., \& Stough, C. (2002). Emotional intelligence and life satisfaction. Personality and individual differences, 33 (7), 1091-1100.

Payne, W. L. (1986). A study of emotion: Developing emotional intelligence; self-integration; relating to fear, pain and desire. Dissertation Abstracts International (University Microfilms No. AAD9-5947), 47 (1-A), 203A.

Podsakoff, P. M., \& Organ, D. W. (1986). Self-reports in organizational research: Problems and prospects. Journal of Management, 12 (4), 531-544.

Rego, A., \& Fernandes, C. (no prelo). Inteligencia emocional: Desarrollo y validación de un instrumento de medida. Revista Interamericana de Psicologia.

Roberts, R., Zeidner, M., \& Matthews, G. (2001). Does emotional intelligence meet traditional standards for an intelligence? Some new data and conclusions. Emotion, 1, 196-231.

Saarni, C. (2000). The social context of emotional development. In M. Lewis \& J. Haviland-Jones (Eds.), Handbook of emotions (2nd Ed., pp. 306-322). Nova Iorque: The Guildford Press.

Salovey, P., \& Mayer, J. (1990). Emotional intelligence. Imagination, Cognition and Personality, 9 (3), 185-211.

Salovey, P., Mayer, J. D., Goldman, S., Turvey, C., \& Palfai, T. (1995). Emotional attention, clarity, and repair: Exploring emotional intelligence using the Trait 
Meta-Mood Scale. In J. W. Pennebaker (Ed.), Emotion, disclosure, and health (pp. 125-154). Washington, DC: American Psychological Association.

Salovey, P., Mayer, J., \& Carruso, D. (2002). The positive psychology of emotional intelligence. In C. Snyder \& S. Lopez (Eds.), The handbook of positive psychology (pp. 159-171). Nova Iorque: Oxford University Press.

Salovey, P., Woolery, A., \& Mayer, J. (2001). Emotional intelligence: Conceptualization and measurement. In G. J. O. Fletcher \& M. S. Clark (Eds.), Blackwell handbook of social psychology: interpersonal processes (pp. 279-307). Malden, MA: Blackwell Publishers.

Scarr, S. (1989). Protecting general intelligence: Constructs and consequences for interventions. In R. L. Linn (Ed.), Intelligence: Measurement, theory and public policy. Urbana, IL: University of Illinois Press.

Schutte, N., Mallouff, J., Hall, L., Haggerty, D., Cooper, J., Golden, C., \& Dornheim, L. (1998). Development and validation of a measure of emotional intelligence. Journal of Personality and Individual Differences, 25, 167-177.

Slaski, M., \& Cartwright, S. (2002). Health, performance and emotional intelligence: An exploratory study of retail managers. Stress and Health, 18 (2), 63-68 .

Slaski, M., \& Cartwright, S. (2003). Emotional intelligence training and its implications for stress, health and performance. Stress and Health, 19 (4), 233-239.

Steiner, C. (1997). Achieving emotional literacy. Londres: Bloomsbury Publishing.

Sterns, P. (2000). History of emotions: Issues of change and impact. In M. Lewis \& J. Haviland-Jones (Eds.), Handbook of emotions (2nd Ed., pp. 16-29). Nova Iorque: The Guildford Press.

Tapia, M. (2001). Measuring emotional intelligence. Psychological Reports, 88, $353-364$

Taylor, G. (2001). Low emotional intelligence and mental illness. In J. Ciarrochi, J. Forgas \& J. Mayer (Eds.), Emotional intelligence in everyday life: A scientific inquiry (pp. 67-81). Lillington, NC: Psychological Press.

Taylor, G., \& Bagby, R. (2000). An overview of the alexithymia construct. In R. Bar-On \& J. Parker (Eds.), The handbook of emotional intelligence: Theory, development, assessment, and application at home, school, and in the workplace (pp. 40-67). São Francisco: Jossey-Bass.

Taylor, G., Bagby, R., \& Luminet, O. (2000). Assessment of alexithymia: Self-report and observer-rated measures. In R. Bar-On \& J. Parker (Eds.), The handbook of emotional intelligence: Theory, development, assessment, and application at home, school, and in the workplace (pp. 301-319). São Francisco: Jossey-Bass.

Taylor, S., \& Brown, J. (1988). Illusion and well-being: A social psychological perspective on mental health. Psychological Bulletin, 103, 193-210.

Thorndike, R. (1920). Intelligence and its issues. Harper's Magazine, 140, 227-235.

Thorndike, R., \& Stein, S. (1937). An evaluation of attempts to measure social intelligence. Psychological Bulletin, 34, 275-284.

Wechsler, D. (1940). Nonintellective factors in general intelligence. Psychological Bulletin, 37, 444-445. 
Wechsler, D. (1943). Non-intellective factors in general intelligence. Journal of Abnormal and Social Psychology, 38, 101-103.

Wechsler, D. (1958). The measurement and appraisal of adult intelligence (4th Ed.). Baltimore, MD: The Williams \& Wilkins Company.

Wong, C., \& Law, K. (2002). The effects of leader and follower emotional intelligence on performance and attitude: An exploratory study. The Leadership Quarterly, 13, 243-274.

Zeidner, M., Matthews, G., \& Roberts, R. (2001). Slow down, you move too fast: Emotional intelligence remains an 'elusive' intelligence. Emotion, 1 (3), 265-275 . 